\title{
EFFECTIVENESS OF RASTRA BULOG RICE DISTRIBUTION USING AGENT BASED MODELING AND SIMULATION TOOLS
}

\author{
Roro Arinda Reswanti Julian Pratama*1, Muchammad Rusdan² \\ Universitas Langlangbuana, Indonesia*1, Sekolah Tinggi Teknologi Bandung, \\ Indonesia ${ }^{2}$ \\ roro.arinda@gmail.com ${ }^{\star 1}$. muhamad.rusdan@gmail.com²
}

\begin{abstract}
The Rastra Rice Program is one of the programs planned by the government to reduce the burden on target households. This program provides relief to the community by distributing Rastra Rice which is suitable for consumption. Bulog become one of the state-owned institutions appointed by the government to provide and distribute subsidized rice for low-income groups, the provision prioritizes the procurement of rice/rice from farmers in the country. The main objective of this research is to find a better distribution strategy so that the distribution process of Rastra rice is efficient, minimizes delays from delivery times, and minimizes the risk of storage costs. The research method used is descriptive qualitative with data collection methods using observation techniques and literature studies, while the method in determining the distribution strategy using agent-based modeling and simulation. Agent-based Model (ABM) based simulation method for Rastra rice distribution using the Multi-Agent Simulation (MASIM) stage, namely, the requirements stage, the modeling stage, the design, and architectural stage, the implementation stage, the verification stage, validation, and accreditation.
\end{abstract}

Keywords: Agent-Based Model; Simulation

\section{INTRODUCTION}

The Rastra Rice Program is one of the programs planned by the government to reduce the burden on target households. This program provides relief to the community by distributing Rastra Rice which is suitable for consumption (Satya,2017). Bulog become one of the state-owned institutions appointed by the government to provide and distribute subsidized rice for low-income groups, the provision prioritizes the procurement of rice/rice from farmers in the country.

Rastra Rice Program is not only about carrying out its duties for distribution but about existing business processes. The most important challenge faced by Bulog is in the process distribution process of rice Rastra, where if there is a distribution process flow will have an impact on the accumulation of the number of Rastra Rice that is not distributed to the target households (RTS). The risks that would arise if the distribution were hampered the loading capacity of the warehouse Bulog Division / Subdivre which will lead to costs that will burden the balance sheet Blog. On the other side, Rastra Rice which has been stored for a long time results in rice that is not suitable for consumption by the target household (RTS). For this reason, strategic analysis is needed to determine policies in determining the distribution of Rastra Rice so that no accumulation occurs in the warehouse. In the distribution process, a warehouse can have one or more roles such as warehouse storage for raw materials and components, work-in-process warehouse, finished goods warehouse, distribution warehouse and distribution center, fulfillment warehouse and fulfillment center and local warehouse (Frazelle, 2012).

For this reason, strategic analysis is needed to determine policies in determining the distribution of Rastra Rice so that no accumulation occurs in the warehouse. So, this study aims to introduce the planning concept of the ABMS. An agent-based simulation approach that can analyze the interactions of each individual is called an agent. Each agent interacts with each other with the environment in which they live (Musthapha et 
al., 2013). agent-based modeling and simulation (ABMS) has grown in terms of the number and breadth of applications for agent-based modeling and simulation (ABMS). This application can be applied in almost all disciplines, whether for natural sciences, social sciences, physics, and systems engineering for simulations in engineering, business, operations management, and many more (Macal \& North, 2014).

The main objective of this research is to find a better distribution strategy so that the distribution process of Rastra rice is efficient, minimizes delays from delivery times, and minimizes the risk of storage costs. previous survey stated that rice food security is a complex system, so it takes a single model. One of the modeling methods that are effective for complex systems is Agent Based Modeling and Simulation (Arief, 2013).

Agent-based modeling has been used to study the social phenomenon of human behavior evacuation, pedestrian behavior and processes that occur in business (Julius, 2012). Based on an agent-oriented approach, our research aims to propose a methodological framework that takes into account the impact that a distribution system has on its performances, from the domain model analysis to running the simulation. In this section, we first try to define the problem of modeling the distribution system aspect, then we present the requirements of simulation, and develop in an Agent-Based Simulation context.

Distribution Channel is a set of interdependent organizations (intermediaries) involved in the process of making a product or service available for use or consumption by the consumer or business user (Kotler \& Armstong, 2019). The purpose of a company using the distribution channel is to deliver goods to the consumer, so that distribution channels play an important role in the process of delivering the goods to the consumer or final user.

Agent-based modeling and simulation (ABMS) is a new approach for modeling systems composed of agents that interact autonomously. the ABS is gradually replacing the micro-simulation techniques and object-oriented simulation. This is due to the ability of the ABS to capture different dynamic models which usually consist of simple entities or more complex entities (Musthapha et al., 2013).

ABMS is a paradigm suitable for modeling systems with many decision-makers interacting with each other. ABMS emerged as a major technology to help improve the understanding of the social sciences (Wang et al., 2012).

\section{METHODS}

A conceptual framework is a limitation that will be used to find business solutions to the problems that arise in the process of distribution of rice Rastra. Location of the study conducted in Perum BULOG West Java regional offices, the city of Bandung. This research was conducted from March to December 2020. This study focused on the distribution of rice Rastra just in Bandung.

The research method used is descriptive qualitative, where the approach to be used in this research is the observation technique (Sugiyono, 2011). This observation technique will collect data by looking directly into the field. Then the researcher conducted a literature review related to the simulation model before making the simulation model.

One of the simulation methods that can be used in building ABM is Multi-Agent Simulation (MASIM) (Yin et al.,2011). MASIM is a method focused on developing agent/multi-agent-based simulations. MASIM divided into five stages, namely: (1) Requirements; (2) Modelling; (3) Design dan Architectural; (4) Implementation; (5) Verification, Validation, and Accreditation. 


\section{Requirements}

\section{RESULTS AND DISCUSSION}

The results of research that has been through interviews, surveys, and analysis. First, explain the distribution of rice rastra, second, analyze the behavior of each agent involved in the rice rastra distribution process using a simulation model, and finally apply an agent-based simulation model.

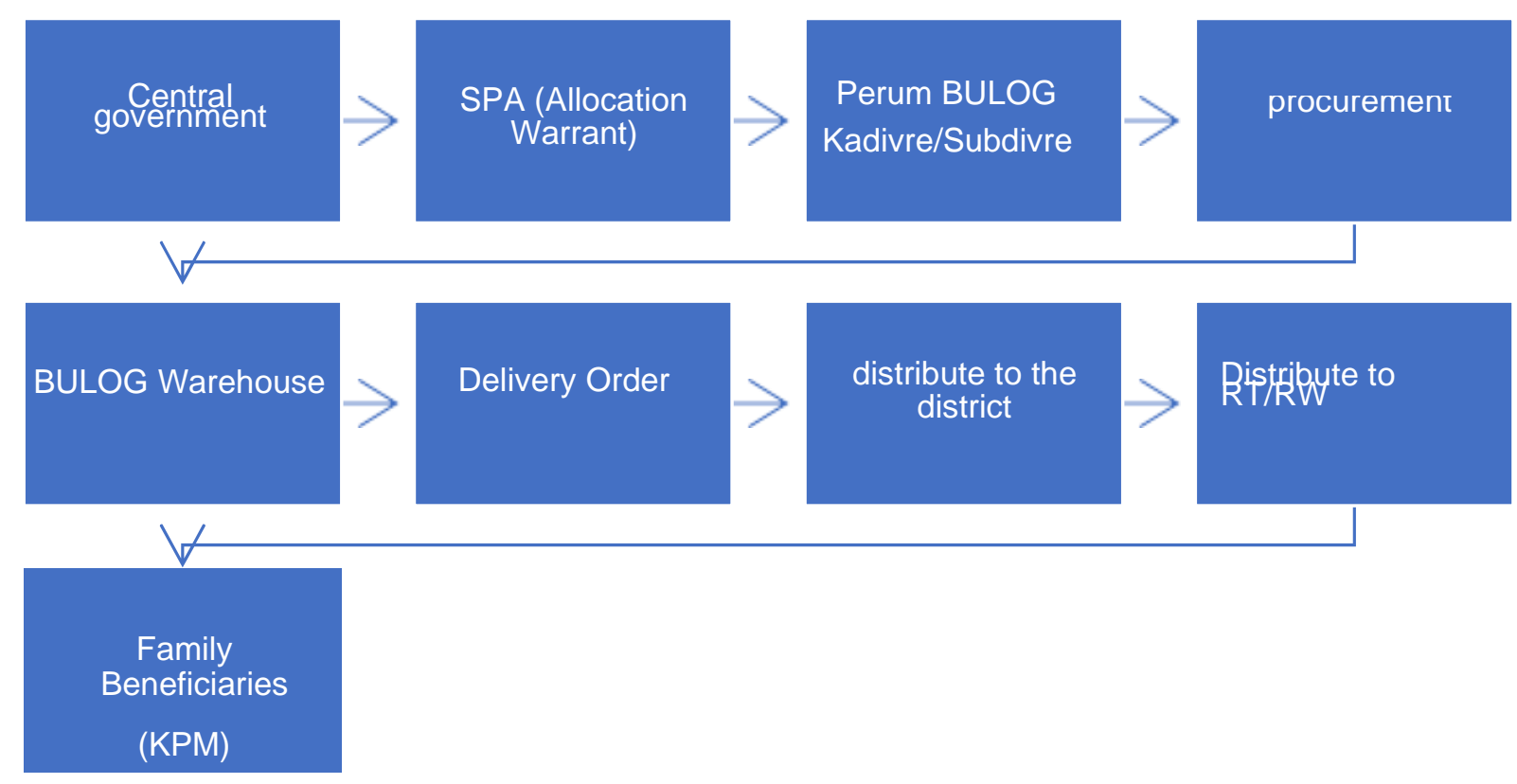

Figure 1. Rice Rastra Distribution Process

Source: Interview (2020)

Based on the results of interviews with Perum BULOG, it was explained that the process of distributing rasta rice at this time began with an order given by the central government to the city/district government of a certain area through an allocation warrant (SPA). Furthermore, SPA will be given to Perum BULOG (KaDivre / Sub Divre) in a certain area. After receiving the SPA, the Perum BULOG will procure goods and check the goods, quality, and weigh the availability of goods to be stored in BULOG's warehouse. Perum BULOG will issue a pass to issue goods (Rastra Rice) from BULOG's warehouse to the District or Village according to SPA data. During the procurement process, up to the distribution process to the distribution point (District / Village party) will be supervised by Perum BULOG. Then the sub-district or village will continue the process of distributing rastra rice to the local RW or RT according to the SPA data which will be given directly to KPM (Beneficiary Family) which has been registered in the SPA and supervised by certain regional governments. 

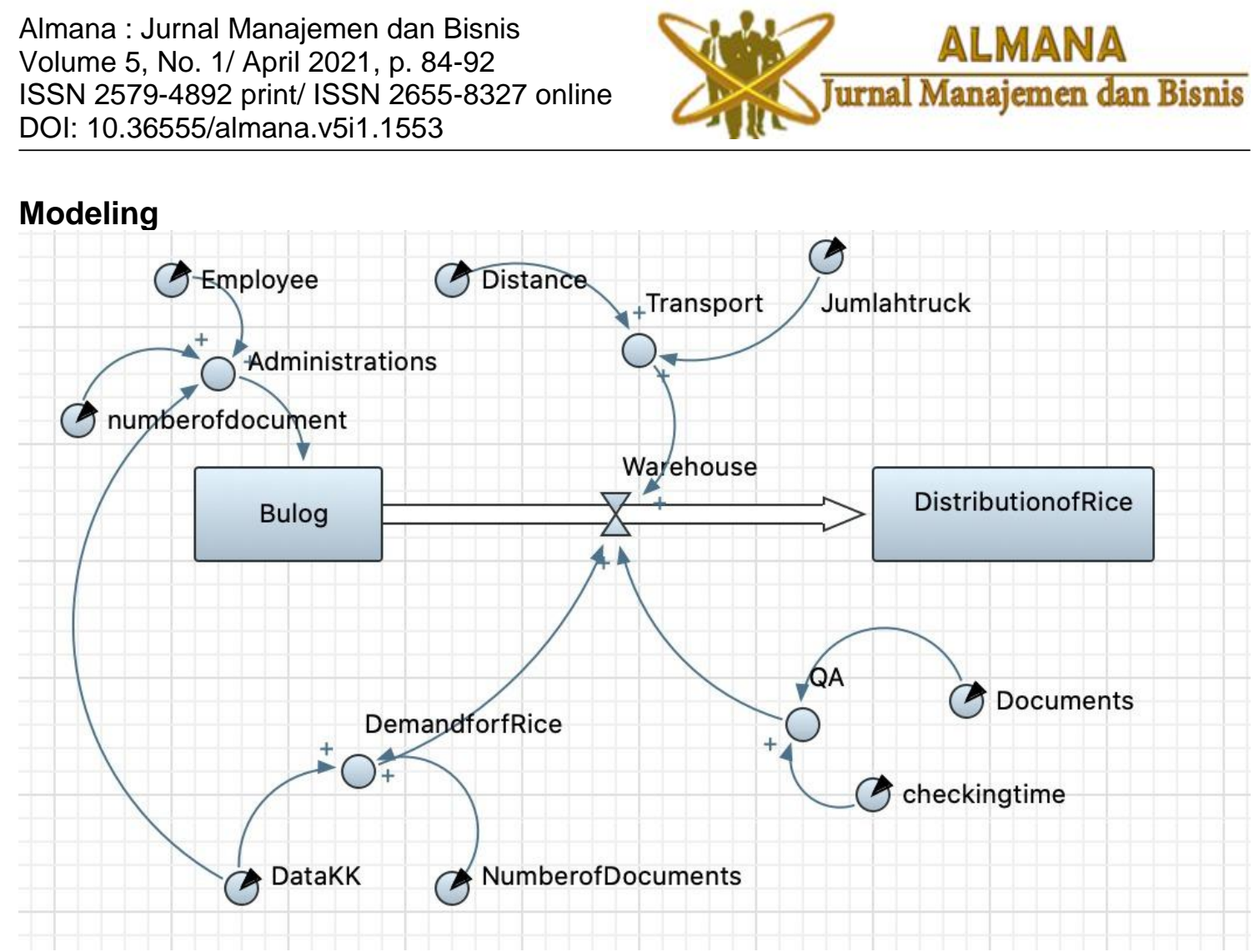

Figure 2. Rice Rastra Distribution Simulation Model

Source: Results of data processing research (2020)

In figure 2 has shown a conceptual framework for the process of distribution of rice Rastra. There will be two agents that affect the output of the agent in this model. Two agents that affect the output of the distribution agent are BULOG and the BULOG warehouse. These two agents will represent every rastra rice distribution activity. At BULOG agents, some variables can affect the process of distributing rice rastra, namely the administrative process in which in this administrative process two sub-variables will affect, among them the number of workers/employees involved in the process of distributing rice data, and the number of documents, where the number of documents is this is the number of recipients of rastra rice aid from the center, Also, another variable that affects is demand, where BULOG needs to procure goods according to the demand for rice by KK data registered from the center.

Furthermore, BULOG will continue the distribution process through the BULOG warehouse, where the BULOG warehouse has an influence in the distribution of rice by checking rice, rice quality, weighing rice, and determining the quality of rice before the rice is distributed to the distributor. Also, the variable that complements the distribution process at BULOG's warehouse is transportation, where this transportation will determine the number of trucks available and the distance for the distribution of the rastra rice.

\section{Design dan Architectural}

At the stage of design and architecture will create a design concept that will be presented in full following the programming approach. This design will explain the role of agents involved views of the nature, value, and description of each (attribute). The total attributes involved in distributing Rastra rice from the Bulog warehouse were 5 PKM attributes with the number of agents involved as many as 32 agents from the attributes 
of each team. The following is a table of agents involved in the distribution of BULOG rastra rice from warehouses to PKM:

Table 1. The Distribution of Bulog Rastra Rice from Warehouses to Pkm

\begin{tabular}{|c|c|c|c|}
\hline No. & Agent Name & Total & Item \\
\hline 1 & $\begin{array}{l}\text { BULOG } \\
\text { Agent }\end{array}$ & 8 & Person \\
\hline 2 & $\begin{array}{c}\text { BULOG } \\
\text { Warehouse } \\
\text { Agent }\end{array}$ & $\begin{array}{c}11 \mathrm{~s} / \mathrm{d} \\
21\end{array}$ & Person \\
\hline & Transportasi & & \\
\hline 3 & Agent & 2 & Person \\
\hline 4 & $\begin{array}{l}\text { Sub-District } \\
\text { Agent }\end{array}$ & 8 & Person \\
\hline 5 & Village Agent & 5 & Person \\
\hline
\end{tabular}

The total number of agents involved in the distribution process of Bulog rice from the warehouse to PKM. The BULOG agent involved as many as eight people, where the roles and behavior of each agent had different behaviors. Also, there are 11 to 21 agents in the BULOG Warehouse, where the BULOG Warehouse agents have roles as warehouse head, clerk, weigher, transporter, and administration. Then for the BULOG transportation agent involved only two people where the agent was the driver and transporter. Furthermore, the sub-district agent has a total of eight agents, of which the agents have their respective roles.

Implementation

At this stage, we will apply the simulation model design results that have been created using the simulation programming language. The programming simulation language that will be used in this research is Anylogic Software. Anylogic Software is a simulation modeling tool with various methods, where this tool can support agent-based simulations.

Furthermore, this implementation phase will develop simulation scenarios, the scenarios will be tested by comparing the model scenarios under normal conditions and simulation. The scenarios in conditions obtained from field observations give the following results:

\section{First Scenario - (Normal Condition)}

In scenario 1 will use the normal condition, where the normal condition will be run by the results of observation. In normal conditions, three agents will be involved, namely, BULOG, BULOG warehouse, and rice distributors. In each of these, there will be a variable agent of mutual influence and are influenced as the administration will affect Bulog to procure rice, which this administration will be influenced by the number of workers involved in the administration and the number of recipients Rastra rice. KPM's number of recipients to be tested is of the data in 2019 as many as 60988 . time to be simulated in scenario 1 in units daily. Also, the number of trucks used is 1 truck/day. 

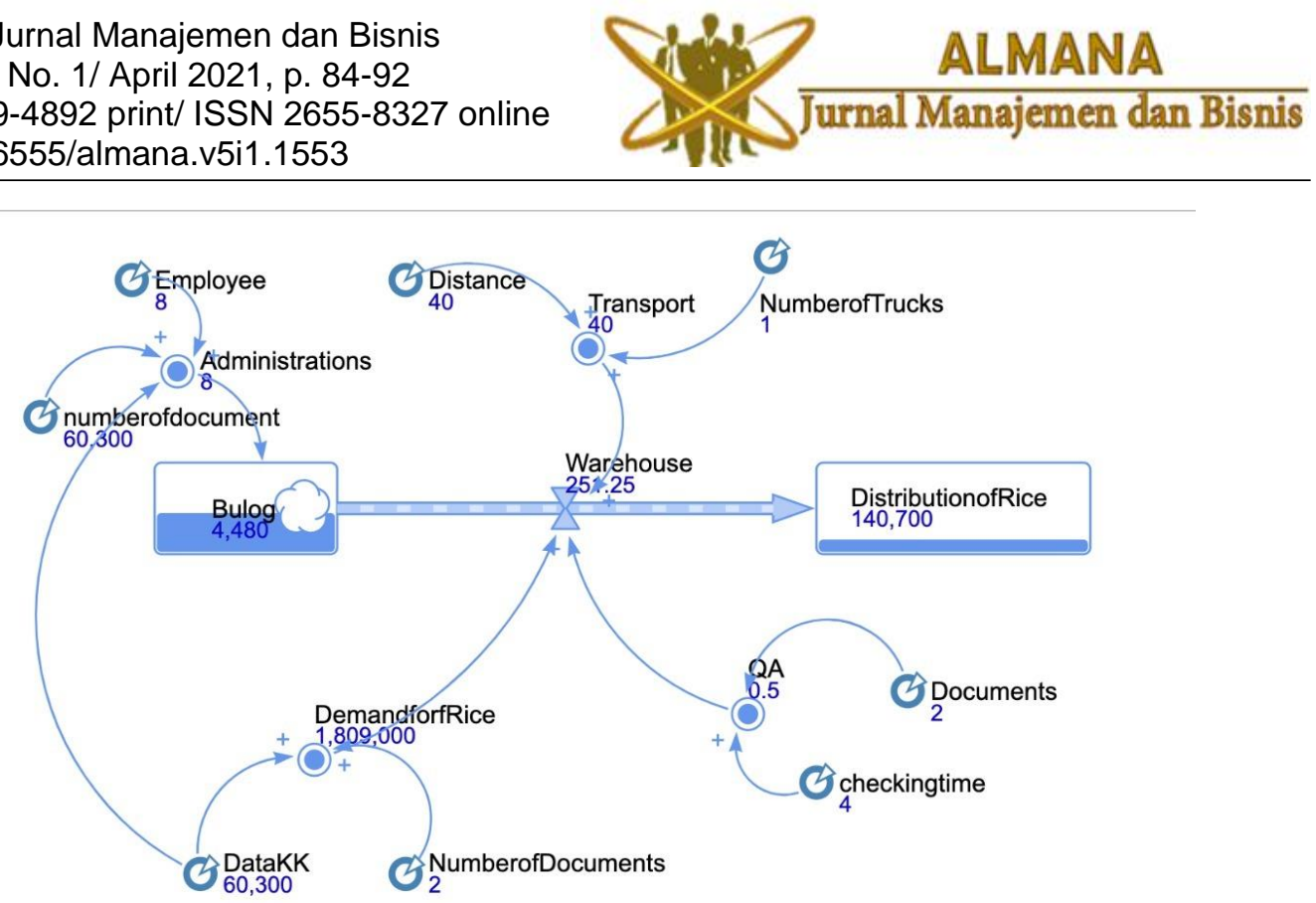

Figure 3. First Scenario

Source: Results of data processing research (2020)

From the graph in Figure 3, the condition 1 scenario shows that the simulation results in this condition are not optimal in distributing rastra rice. This is caused by the administrative process is not balanced with the amount of demand for rice. Also, the process Warehouse Bulog rice received from a partner is not to be selected, and the number of trucks used in these conditions only one truck per day. This is the one that becomes not optimal in the process of distribution of rice Rastra look at those results can only distribute rice amounted to 140.700 tonnes.

\section{Second Scenario - (Simulation Condition 1)}

In the second scenario, a simulation condition will be used using data modification 1 by increasing the transportation agent. This is intended to compare which one is more effective than the current time. In scenario two, the agent data that will be used is still the same in the previous scenario. However, this second scenario will do data modification agent used in the process of distributing rice Rastra.

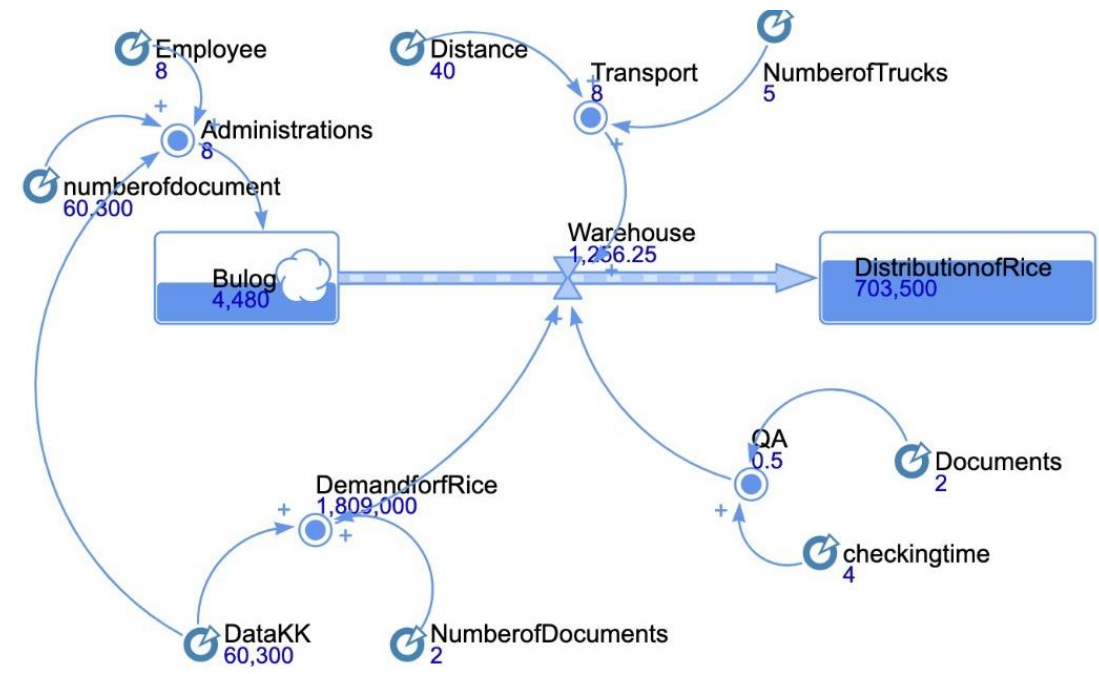

Figure 4. Second Scenario

Source: Results of data processing research (2020) 
Figure 4 shows a distribution chart with a data modification model, where the data agent is involved in the rice distribution process. In the second scenario, the number of inputs at Bulog is still the same, but the amount of activity in Bulog warehouses will be improved agent used truck that will increase to five trucks per day. So, it can be seen from the results that the distribution of rice will be more optimal as seen in the amount of rice distribution that will increase by 703,500 tons if the number of trucks used is increased.

\section{Third Scenario - (Simulation Conditions 2)}

In the third scenario, will use the simulation to improve the conditions at the input's agency Bulog is an administrative agent and on Bulog warehouse processes, such as transport. It is intended to compare which one is more effective than the first scenario, the second scenario, and the scenario by a third.

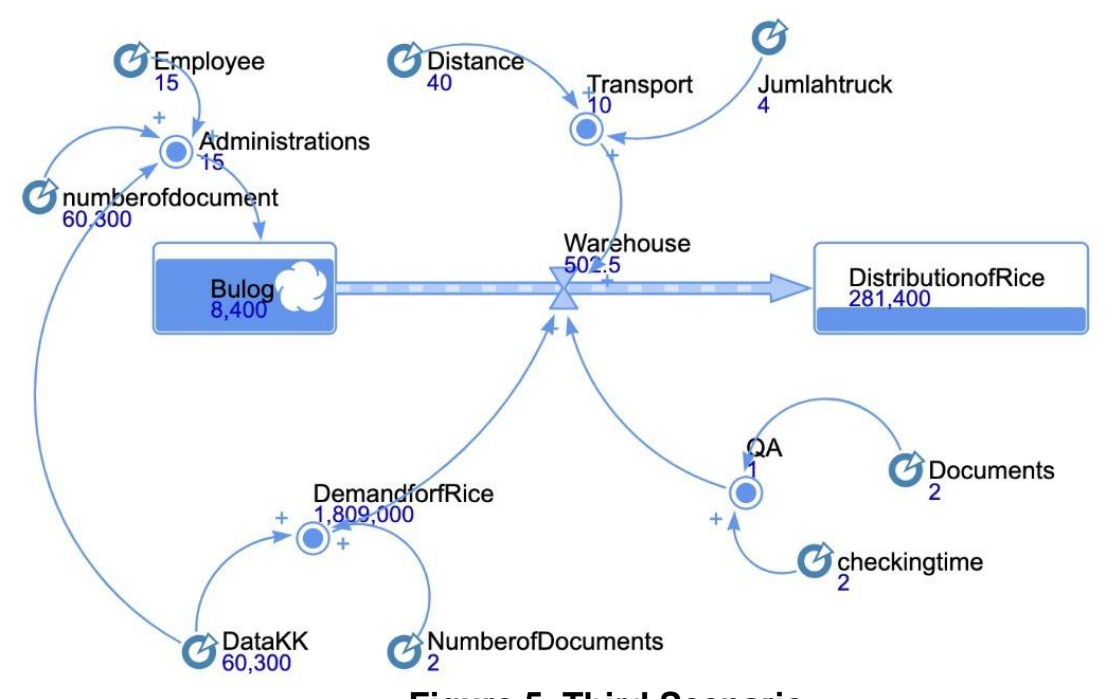

Figure 5. Third Scenario

Source: Results of data processing research (2020)

Figure 5 shows the simulation results of the rice distribution process by increasing the number of agents involved in the rice distribution process. The third scenario provides a more optimal result compared to scenarios 1 and 2 looks at the output of the distribution of rice to distribute rice at 281.400ton. in this condition, it has improved the activities carried out by each agent involved by increasing the number of agents in administrative input and the BULOG warehouse process, especially in transportation, so that the results will be more optimal than the conditions in scenario 1 and scenario 2. Also, the amount of output produced in scenario 3 is almost close to the target achievement that must be met by the BULOG team at Perum BULOG Bandung

\section{Verification, Validation, dan Accreditation}

At this stage, the lever aims to ensure that the simulation model is correct by utilizing the Troubleshoot option in the Analogic Software to see whether the designed model supports simulation. Then the model validation is to determine whether the simulation model created to represent a real system appropriately. The model is said to be valid if the comparison shows that the model and the real system did not differ significantly. 

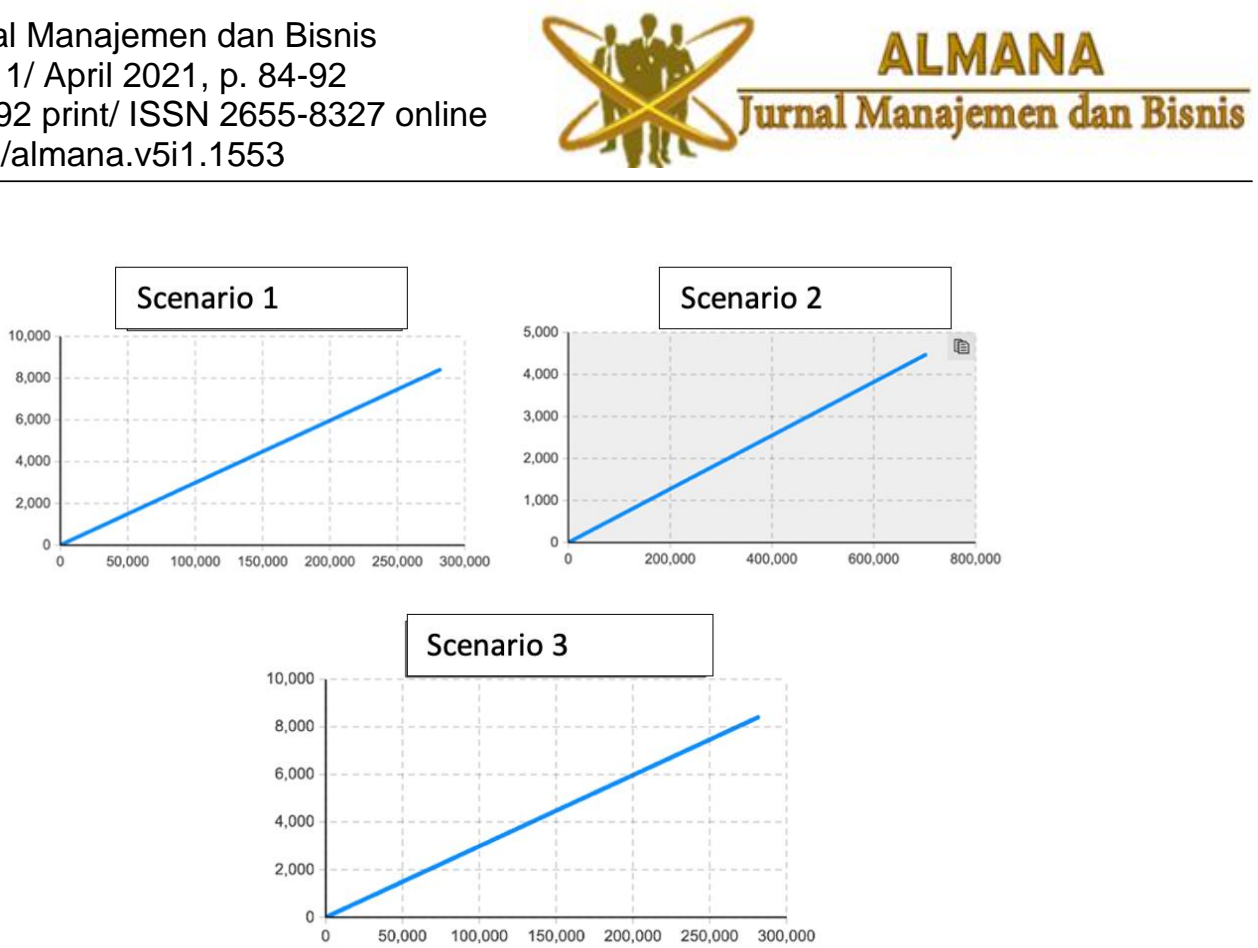

Figure 6. Comparison Chart Scenario 1 Scenario 2 and Scenario 3 Distribution of Rice Rastra

Source: Results of data processing research (2020)

The results of Figure 6 shows that the comparison between the simulation model in scenarios 1, scenario 2, and scenario 3 showed no difference in the model and the real system is too significant. This means that the simulation model can be used to process the distribution of rice Rastra. Based on the three scenarios that have been used in this model, it can be done in selecting the best alternative, namely by using the scenario 3 model which shows that the total distribution of Rasrta rice is closer to its target achievement.

\section{CONCLUSION}

From the research results, Rastra Bulog rice distribution shows that the distribution process is quite good, but several things need to be improved in the process, such as administrative processes that are too complex with several requirements that must be owned. fulfilled as a requirement for state accountability administration (APBN). The distribution of these indications can interfere with the rice distribution process. Also, making process quality standard operating procedures (SOPs) at Bulog's warehouse and procurement.

This research has provided a solution through an agent-based simulation model regarding the effectiveness of the distribution of BULOG rastra rice which can conclude that the scenarios that have been analyzed and tested have different numbers of different treatments. It is caused by the amount of each agent involved in the process of distribution of rice Rastra provides different behavior. Also, the level of accuracy that results from the simulation model is still used daily period. This is due to a lack of detailed information about the accuracy of delivery time and other factors of the Rastra Bulog rice distribution system.

\section{REFERENCES}

Arief, E. (2013). Pemodelan dan Simulasi Berbasis Agen untuk Sistem Ketahanan Pangan Pokok Beras.Tugas Sarjana, Jurusan Teknik Industri, Institut Teknologi Nasional, Bandung. 
Frazelle, Edward. (2012). Supply Chain Strategy. McGraw-Hill. New York.

Julius, Bata. (2012). Simulasi Berbasis Agen-Based Modeling (Abm) Menggunakan Netlogo. Issn: 2089-9815

Kotler, Philip \& Armstrong, Gary. (2019). principles of marketing, eighth edition.

Macal, Charles M \& North, Michael J. (2014). A theoretical formalism for analyzing agentbased models. Complex Adaptive Systems Modeling 2(1): 3.

Musthapha, Karam. Mcheick, Hamid. Mellouli, Sehl. (2013). Modeling and Simulation Agent-Based of Natural Disaster Complex System; Quebec; Canada

Satya, S. 2017. Pedoman Umum Subsidi Rastra. Jakarta.

Sugiyono. 2011. Metode penelitian kuantitatif, kualitatif dan R\&D. Bandung: Alfabeta.

Wang, Yu., Luangkesorn, K. Louis., Shuman, Larry. 2012. Modeling emergency medical response to a mass casualty incident using agent-based simulation.

Yin, Q., Li, Y \& Zhi, K. 2011. Multi-Agent-Based Simulation of Negotiate Pricing Process in B2C. Second WRI Global Congress on Intelligent Systems. 